\title{
Gente alta é parente do tuiuiú, baixa é da anta: alteridades antropomórficas
}

\author{
Adriana Werneck Regina
}

\section{Introdução}

Este artigo se desenvolve a partir de duas narrativas míticas explicativas do aparecimento da mulher na realidade do povo Panará, uma envolvendo a metamorfose do Jaburu ${ }^{1}$ (jabiru mycteria), outra, da Anta (tapirus terrestres). $O$ foco é discutir aspectos de uma noção de corpo que se revela na maneira de conceber a transformação corporal do Jaburu e da Anta, e também do corpo humano panará e da maneira deste povo viver, desdobrada da relação de um homem com o Jaburu e com a Anta na ancestralidade. Notadamente, tem o interesse em debruçar-se nas mudanças no mundo com o aparecimento das mulheres e em como a diferenciação das espécies anunciada no tempo mítico está conectada às específicas fisionomias dos corpos humanos: A mulher tuiuiú não era baixinha, era alta; o homem também era alto, até hoje consideramos que a mulher alta é parente do tuiuiú (M. 2012).

A alteridade contorna este assunto e nos remete a Ewart (2000), que explorou centralmente a relação com o outro em seu estudo. Quando a autora se refere às narrativas míticas, enfatiza o fenômeno de que as antigas pessoas, ligadas às distintas espécies, perderam os atributos que eram parte da sua condição humana, virando animais. Põe em destaque como a aquisição de coisas e de práticas culturais ligadas originalmente a elas, pelos panará humanos, acompanhou a distinção das mesmas, fazendo aparecer sua animalidade, configurando um mundo em que unicamente o panará experimenta como pessoa, dentro do espaço social dos seres humanos, tais aquisições. A cutia, o rato, o mutum e outros eram concebidos como panará quando eram gente e a metamorfose impôs-se como uma diferenciação entre panará e não-panará (Ewart 2000: 150). Em sua abordagem, reiterou aquela premissa de Viveiros

1 Sabe-se que esta ave é uma das maiores da América do Sul. Ela chega a atingir entre 1,10 m a 1,40 m de altura. Esclarece-se que ao longo do texto foi adotado o nome "jaburu” à referida ave ao invés de "tuiuiú", conforme consta no título. 
de Castro (2002) tangente à indistinção da condição de humanidade entre os seres na ancestralidade, afirmando-a como universal.

No entanto, gostaria ainda de aprofundar outras questóes que aparecem acerca deste fenômeno da transformação, particularmente a vinculada ao jaburu e à anta, pondo em relevo o valor dado a um corpo poder tornar-se muitos e à fisionomia da espécie humana, intrinsecamente ligada à maneira de simbolizar ambas as espécies, algo ainda pouco discutido nas etnografias deste povo. Ademais, determinados aspectos da noção de corpo que serão demonstrados a partir destes contextos relacionais do homem panará com a anta e com o jaburu, na ancestralidade, contornam outras maneiras de compreender o significado dos clãs e do matrimônio, igualmente vinculados, por sua vez, à maneira de simbolizar ambas as espécies. A argumentação é criada explorando os contextos significativos que as pessoas panará mobilizam quando explicam as histórias do jaburu e da anta, e quais estão presentes nas narrativas em si mesmas, e também pelo exercício de apresentar comportamentos sociais cujos sentidos que os orientam e os justificam têm relação de continuidade com aquelas condições sociais rememoradas pelas referidas histórias. Não pretendo, como resultado deste empreendimento, alcançar uma concepção de corpo definida, passível de ser fixada como uma verdade representativa do ponto de vista de mundo do povo Panará. A intenção é esboçar alguns aspectos de como o corpo é percebido, sob a perspectiva de que pode haver outras variações e nuances passíveis de serem identificadas, conforme a ampla possibilidade de conexões que um mesmo povo pode conceber em relação ao que nós categorizamos como corpo.

Tomando o idioma da corporalidade como temática central deste artigo, tem-se que o mesmo foi contemplado no estudo de Schwartzman (1988). Todavia, é preciso discernir que a sua construção argumentativa foi pautada pela identificação de um modelo de produção e reprodução de pessoas, articulado à circulação dos homens da casa familiar para a casa central e depois para a residência de seus sogros. Na forma como o corpo foi abordado há a ênfase no amadurecimento biológico e social subjacente à construção de laços de afinidade envolvendo a matrilinearidade e a uxorilocalidade.

Ele abrange as furações no lóbulo e no lábio, praticadas nos meninos, analisando-as como reforço dos laços consanguíneos. A primeira simbolizando a incorporação de pessoas na família-natal, a segunda marcando a incorporação dos meninos na ikâpy (casa dos homens), no centro da aldeia, onde passam a dormir e a receber ensinamentos dos mais velhos. E, depois, as escarificações nas coxas, ocorrida nas roças no período da colheita de amendoim, associando-as aos laços de afinidade criados pelo casamento (esta intervenção corporal não se pratica mais atualmente). Impõe-se o seu interesse em retratar o funcionamento de uma estrutura social, cujo horizonte não opera na minha intenção de compreender alguns aspectos da noção de corpo panará. Ao invés disso, priorizo elucidar específicos contextos relacionais que poderão ser articulados com outros, a serem melhor investigados posteriormente, sem a perspectiva de que uma estrutura anteponha-se a eles, enquanto um referencial sistêmico e totalizante. Ademais, os laços de consanguinidade e de afinidade impuseram-se como parâmetros na sua ordenação de como a fabricação social do corpo é estruturante e estruturada socialmente. Embora o sistema de parentesco seja relevante na constituição semântica de uma noção de corpo, pretende-se explorar outros significados que possibilitam acessar outras expressões sociais adjacentes à maneira de 
os panará perceberem o jaburu e a anta e de com eles se relacionarem, sem perder de vista a presença dos referenciais de afinidade, cuja relevância Schwartzman (1988) esclareceu. Ganha importância discutir o aparecimento da mulher na realidade panará, possibilitando o matrimônio enquanto um contexto social de ação.

Ainda no campo da corporalidade, Ewart (2000, 2005), por sua vez, elegeu suakin e suangka como dois estados físico-psicológicos decisivos para a sociabilidade no cotidiano. O primeiro indica o ânimo e a disposição para caçar, pescar, dançar, coletar, ir à roça, pintar-se, brincar, conversar; o segundo, contrariamente, representa o estado de isolamento, tristeza e recuo da vida social. Ela analisa que o estado suangka prolongado reduz a intersubjetividade, limitando a vida social. Defende, por fim, que as relações interclânicas em torno do casamento, das cerimônias e da produção de alimento são veiculadas pela condição suakin, sintetizando que significa estar disponível para os outros. Enfatiza a relevância destes conceitos nativos na dinâmica da socialidade. A autora explorou outra dimensão da corporalidade, valorizando as relaçóes contingentes no cotidiano, onde os referidos estados operam, e esclareceu como a disposição em se relacionar com o outro é relevante como base para os contextos de ação se realizarem como tais. De modo articulado a isso, permaneceu pondo em evidência a produção de pessoas e de alimentos, fazendo a conexão dela com a construção de laços de afinidade, por sua vez, intrinsecamente ligados à exogamia e à uxorilocalidade, reiterando, neste ponto, o estudo de Schwartz$\operatorname{man}(1988)$.

Ambos os autores ofereceram muitas contribuições esclarecendo a dinâmica inter-clânica e da construção de alianças matrimoniais, combinadas ao esclarecimento de algumas maneiras de circular pessoas e alimentos. Pretende-se aprofundar outros aspectos de como o corpo é percebido, explorando temas ainda pouco discutidos, abordando a animalidade e a humanidade articuladas no corpo humano panará, contornando uma maneira de se perceber e o jaburu e a anta. O texto desenvolvido esquiva-se de uma pretensão explicativa, antepõe-se como uma experiência ainda de teor investigativo, mas que pretende expandir as contribuições desenvolvidas até então, pelos referidos autores.

O perspectivismo ameríndio, formulado por Viveiros de Castro (2002), apresenta uma explicação de como a relação social entre as distintas espécies é cogitada, contemplando a ingerência da noção de corpo como base fundante dela, sendo que esta última já vinha sendo observada e debatida no final dos anos 80 do século passado. Seeger, Da Matta e Viveiros de Castro (1987) explicitaram a relevância do idioma da corporalidade no estudo dos povos ameríndios, à medida que o corpo, entre eles, impõe-se como palco de práticas que visam à sua transformação, correlacionando-a com as alterações de posições sociais, políticas, cerimoniais e do conjunto de direitos e deveres a elas relacionado. Uma discussão que possui relação de continuidade com as reflexões de Mauss (2003), que argumentou que todo comportamento ligado ao corpo é construção cultural, reconhecendo as múltiplas possibilidades de com ele se relacionar.

Importa, aqui, articular este debate acerca do corpo com as condições de humanidade e animalidade como ferramentas conceituais. Na cosmovisão ocidental, a espécie humana é classificada como parte do reino animal, no entanto ela é distinguida dos demais seres que igualmente são reconhecidos como parte dele por ter desenvolvido a linguagem, bem como uma relação dinâmica com o ambiente 
mediada por ferramentas e maneiras de organizar o uso delas que o alteram, além de inventar regras incorporadas como orientadoras de comportamentos. A consciência, a linguagem, a reflexividade, a inventividade, a regra e a moral compóem o conjunto de argumentos que têm sido destacados para diferenciar a humanidade da animalidade. Trata-se de expressões imateriais que contrapõem-se àquelas da animalidade, orgânicas e observáveis empiricamente, inatas e instintuais. Os comportamentos artísticos, religiosos, míticos, éticos e linguísticos são apreendidos como manifestações de caráter cultural possibilitados pelos atributos da humanidade. Descola (1986; 1992; 2001), Ingold (1995; 2004) e Viveiros de Castro (2002) rompem com os contornos semânticos desta diferenciação enfatizando a superioridade humana e propõem ressignificar estes atributos, antes ligados ao homem, como qualificadores de uma condição específica, a de humanidade, convertendo-a em instrumental conceitual, aberto à possibilidade de subvertê-los como exclusivos da espécie humana. O que é concebido como natureza e cultura passa a ser modulado de acordo com a cosmopráxis de um povo (Descola \& Pálsson 2001), dado o reconhecimento da não universalidade de tais noções. No campo deste debate, a epistemologia dos povos que reconhecem o estatuto de sujeito dos diversos viventes é compreendida de diferentes modos. Descola $(1986$; 2001) definiu o animismo como um sistema de ideias em que as categorias sociais são modelos para organizar a forma de relação simétrica entre as existências, havendo uma continuidade entre natureza e sociedade. Em sua formulação teórica, baseada na existência de finitos esquemas mentais que ordenam as formas de relação humano-natureza, o animismo é uma das diferentes formas de objetivar socialmente a natureza. Em contraposição, Viveiros de Castro (2002; 2012) destaca a condição de sujeito, e não a de humano como uma referência antropocêntrica e metafórica para compreender os animais e as plantas, o que parece se aproximar mais do ponto de vista panará no sentido de reconhecer o estatuto da subjetividade do jaburu e da anta como verdade corporificada. Ainda inserida na formulação deste autor, é imperativa a redefinição do que seja social a fim de considerar outros fenômenos possíveis percebidos como constituintes de uma relação. Não são focadas as relações sociais que constituem seu objeto, mas o que o seu objeto constitui como relação social (Viveiros de Castro 2002: 122). Neste particular, uma distinção é apresentada em sua abordagem, porque não depende somente das relações sociais, mas de como são definidos os estatutos das existências percebidas e presentes no mundo possível. Aqui, tem relevância o que é qualificado como sujeito ou objeto contornando o que é apreendido como palco de uma relação. A condição humana é genérica, o que significa universalizar a posição de sujeitos de distintas espécies animais. Sendo assim, elas também são capazes de ter um ponto de vista, exprimindo uma cultura. Por extensão, as relações entre animais e pessoas são de caráter social. Há diferenças de perspectivas entre as pessoas envolvidas numa relação conforme a qualidade da natureza das mesmas. Um predador pode ver-se a si mesmo como humano, bem como a outro membro de sua própria espécie, já uma presa é percebida por ele como animal, sendo que ela vê a si mesma como humana e o predador como um espírito. As diferenças de pontos de vista são, portanto, relacionais, retratam distintas perspectivas de mundo. A diferença da natureza das pessoas que estão em relação é que constitui as alterações dos significados. Uma pessoa pode ser vista como cunhado, presa ou espírito de acordo com quem estabelece uma interação. Os pontos de vista alteram o mundo e não o mundo os altera, e os mesmos são construídos de acordo com a relação em 
que se está inserido. A metamorfose é contemplada em sua argumentação revelando, paralelamente, uma explicação acerca da noção de corpo dos povos ameríndios sul-americanos. O autor afirma que a alteração da forma corporal não subverte a condição de sujeito, mas altera o que é visto por ele em uma situação relacional, dando sentido ao nome perspectivismo, enfatizando relações com o outro sob o pressuposto da diferença de perspectivas.

É intrigante estudar como as relações sociais com o Jaburu e com a Anta foram constituídas e como elas mesmas constituíram o corpo físico dos panará, abrangendo não só as manifestações que denunciam a universalidade da condição de humanidade, mas aquelas que apontam uma transversalidade de aspectos da animalidade no jaburu, na anta e no humano. Neste particular, é enfatizada aqui a alteridade antropomórfica dos corpos humanos sob o ponto de vista do povo Panará, classificado como jê setentrional.

Ademais, recentemente, as reflexões de Wagner (2012) ainda provocam a revisão crítica de que os próprios termos que embasam a elaboração de um tema de estudo são invenções culturais. O que é delimitado como noção de corpo confunde-se com a criação de que existe uma noção de corpo, provocando a necessidade de dar atenção a quais são as tendências do que se cristaliza como expressão dessa noção entre os panará, evitando as limitações que podem se impor a esta compreensão e promovendo a recriação da própria concepção em foco.

A discussão está embasada em diários de campo pessoais, confeccionados quando convivi com as famílias panará na aldeia Nãsêpotiti, na Terra Indígena Panará (região fronteiriça do Norte de Mato Grosso e Sul do Pará, entre os municípios Guarantã do Norte-MT e Altamira-PA), por ser integrante de uma equipe indigenista do programa de educação do Instituto Socioambiental (ISA), ao longo de 1988 e 1999. Somam-se os registros construídos a partir de um seminário intitulado "Mapeamento das Mitologias"2 ocorrido em 2012, em Poconé-MT, quando os três participantes panará contaram histórias dos antigos, acompanhadas de enunciados explicativos espontâneos acerca delas. $\mathrm{O}$ resultado da minha pesquisa de mestrado ${ }^{3}$ é outra relevante experiência abarcada nesta busca investigativa, e que despertou a vontade de centrar a atenção nos eventos etnográficos que circunscrevem uma noção de corpo, o que faz parte do meu tema de pesquisa no doutorado que atualmente estou vivenciando.

\footnotetext{
2 Escutar as histórias dos antigos de distintos povos do Mato Grosso com a finalidade de discutir as ameaças e pressões contra os seres e os lugares destacados nestas narrativas foi o objetivo deste evento. Ele foi promovido pela parceria entre o Grupo Pesquisador em Educação Ambiental (GPEA) da Universidade Federal de Mato Grosso e a Operação Amazônia Nativa (OPAN), uma organização não- governamental atuante na causa indígena, em 2012.

3 No meu mestrado, concluído em março de 2013, estudei a concepção de aprendizagem do povo Panará sob a perspectiva de articulá-la à noção de natureza, discutindo os contextos de alteridades entre humanos e não-humanos que dão sentido aos aprendizados de diversas práticas sociais, contemplando a agricultura, a preparação de alimentos, cerimônias do matrimônio, da colheita de amendoim, entre outras. A dimensão da relação entre humano e não-humano foi explorada promovendo o encontro com um sistema de pensamento em que a possibilidade de um corpo tornar-se outro pareceu expoente.
} 


\section{A história da relação com o Jaburu}

Com apoio nas diversas versões da história do jaburu, contadas por pessoas diferentes ${ }^{4}$, abrangendo aquelas registradas nos estudos de Schwartzman (1988) e Ewart (2000), observa-se que esta condição de vida "sem mulher" aconteceu como uma experiência dos homens panará, particularmente, sendo sinalizada a presença feminina em outras coletividades, o que nos aponta a heterogeneidade entre elas. O corpo humano feminino panará apareceu da transformação do Jaburu e a história que relata este episódio não é avaliada, contudo, como sendo sobre a origem da mulher num mundo absoluto para todos os seres. Trata-se, antes, de fazer aparecer a mulher humana Panará. Nesta oportunidade, registro o enunciado: O homem viu a vagina do Jaburu, ela tinha pelo no púbis, a da anta não tem para ilustrar também a importância dada à vagina como uma expressão física do corpo feminino que, por sua vez, também é distinta entre as diversas coletividades. A do jaburu tem pelo, a da anta não tem.

A história do Jaburu inicia particularizando um homem que tinha retirado um filhote de jaburu de seu ninho e da mata com o objetivo de criá-lo na aldeia e que, desde então, todo dia lhe dava comida. A fim de caçar e pescar por uma temporada prolongada, saiu à mata levando o filhote consigo. Em cada acampamento que fazia, construía um lugar para aninhar a ave e sempre a alimentava com peixe cru. Quando ele pescava e caçava, o pássaro virava "como gente" e coletava folha de bananeira para embrulhar e assar bolo no forno de pedras, preparava água e a esteira de dormir para o homem, depois retornava ao ninho "como pássaro". O homem conversava com o filhote dizendo: "Vou pegar peixe para você", e o jaburu respondia "sim" balançando a cabeça. Em cada acampamento, esta ave se transformava, preparava a fogueira e a comida e, em seguida, subia ao ninho como jaburu. Este pássaro virava como gente e fazia comida para ele (M. 2012). Durante meses, isso persistiu deixando-o muito intrigado sobre quem lhe preparava alimento. Um dia resolveu fingir que ia pescar e se escondeu para tirar a dúvida se era o pássaro que fazia isso. Testemunhou o jaburu virar mulher e ela, percebendo que tinha sido vista, nunca mais virou pássaro. Ela justificou que cuidava dele por vê-lo triste e sozinho. Os dois resolveram se casar e a mulher não virou mais pássaro: Não é mais aquele pássaro, ela conversou que não vai mais deixar ele sozinho (M.2012).

O corpo do Jaburu aparece de diferentes formas circunscrevendo a metamorfose como uma imanência, na ancestralidade, dificultando eleger uma delas como uma referência central. No entanto, o antropomorfismo foi estabilizado quando o homem descobriu a transformação do Jaburu. A equivalência entre jaburu-ave e jaburu-gente inscreve-se na simbolização deste específico corpo, sobrepondo a referência de um mesmo sujeito na forma de gente e de ave. O homem Panará, portanto, se casou com o pássaro jaburu tornado gente, isto é, com a jaburu-gente e não com uma categoria genérica e impes-

\footnotetext{
4 As narrativas míticas consideradas neste estudo contemplam os textos escritos em Língua Portuguesa de autoria dos jovens panará em contexto de atividades pedagógicas e as narrativas orais emitidas em Língua Panará traduzidas em Língua Portuguesa na aldeia Nãsêpotiti, ao longo de 1988 e 1999, registradas em diários de campo de modo fragmentado, bem como aquelas enunciadas no seminário “Mapeamento das mitologias”, promovido pela OPAN e o GPEA da UFMT, em 2012, gravadas em audiovisual, além das transcrições registradas nas monografias de Schwartzman (1988) e Ewart (2000) na Língua Panará e traduzidas em inglês. O resumo apresentado foi editado por mim, abrangendo os conteúdos presentes nestas referidas fontes.
} 
soal, traduzível como exemplar da espécie humana (homo sapiens). Trata-se do aparecimento de uma mulher-jaburu na realidade do povo Panará, cuja subjetividade é singular.

Anteriormente à fixação do Jaburu "como gente", o sofrimento e a solidão são qualidades que caracterizam a vida dos homens "sem mulheres". A presença feminina aparece correlacionada à superação delas, fazendo emergir a parceria entre homem e mulher: o homem não fica mais sozinho agora. Esta transição para uma condição de vida "com mulheres" é apreendida positivamente, sugerida como uma iniciativa feminina.

"Foi você que estava fazendo comida para mim". "É, fui eu, porque você estava muito triste, não tinha a sua parceira para fazer comida para você, por isso eu me transformei para cuidar de você”. Aquele homem chegava do mato, tinha que fazer comida. Aí, eles conversaram, o pássaro resolveu e eles se casaram. (M. 2012).

Quando o narrador afirma “o pássaro resolveu”, denuncia a percepção de que a metamorfose não subverteu a referência do pássaro inscrita no jaburu-gente que decidiu se casar com o homem panará, reiterando a premissa de que se sobrepõe a subjetividade do Jaburu e não uma de suas formas corporais.

$\mathrm{Na}$ citação acima, observa-se a importância dada à intencionalidade, e é sob este prisma que se compreende a metamorfose, enquanto desdobramento de uma vontade pessoal. Cuidar do homem, neste caso, foi a motivação que configurou a especificidade de uma intenção articulada à transformação.

Preparar e ofertar o alimento, assim como ajeitar a esteira de dormir, foram manifestações contempladas como sendo de "cuidar", caracterizando a parceria, aqui valorizada. Deslocando-nos da fala e das ações do Jaburu, rapidamente, podemos recuperar que o homem cuidava de seu filhote desde quando ele o tirou da mata, o que revela a manifestação deste desejo de "cuidar" no homem, reconhecendo nele, portanto, tal iniciativa. Sob este prisma, o Jaburu pode ser abordado como respondendo a estes cuidados. "Cuidar" se converteu numa ação mútua entre o homem e a mulher, formatando um atributo do que é significado como parceria.

O pássaro e o homem decidiram se casar; o matrimônio faz parte da condição de vida "com mulheres", subvertendo o fato de que o homem morava sozinho, de acordo com outro argumento associado a esta história em discussão. Morar junto, portanto, também compõe este sentido dado à parceria. Podemos avaliar, então, que a metamorfose do Jaburu está vinculada ao matrimônio, ao morar junto e à mulher ser cuidada pelo homem, cuidando dele também. Ademais, importa destacar que o homem pegou um filhote de jaburu para cuidar, o que nos remete às práticas dos antigos panará de homens se casarem com crianças, comprometendo-se a delas cuidarem. Fica sugerida uma combinação entre matrimônio, cuidar e filhote. Sob este ângulo, reaparece o contorno de um cuidado iniciado pelo homem, reiterando o seu desejo de ter alguém junto para tanto. Em nossa contemporaneidade, testemunha-se o interesse de adultos construírem alianças matrimoniais com mulheres bem mais novas.

A narrativa ainda segue demonstrando que o aparecimento da mulher não se resumiu à metamorfose do Jaburu. Ele esteve coadunado à potência de um corpo tornar-se muitos. A simbolização do jaburu expande-se para a perspectiva de um corpo virar muitas mulheres, o que tornou possível o casamento e o cuidado mútuo serem experiências dos homens panará em geral, e não só daquele homem e do filhote, particularmente. A experiência de um homem foi replicada para muitos, o que significa 
dizer que a experiência da mulher ser cuidada pelo homem, cuidando dele, abrangeu mais mulheres-jaburus transformadas e mais homens panará.

A partir de uma entrevista com uma toatum (mulher mais velha), registrada por Schwartzman (1988), fica esclarecido que os clãs passaram a existir na realidade panará como decorrência da história do Jaburu que, por sua vez, está associada à ideia de multiplicação do corpo. Ela conta que quando os homens foram para a aldeia do jaburu, surpreenderam-se com a grande quantidade de casas e de pessoas.

Consonante com isso, no contexto do mencionado seminário, o narrador panará constrói uma narrativa distinguindo o momento da transformação da ave em gente daquele da multiplicação de um corpo em vários.

Aí, este pássaro desceu e virou como uma mulher, uma mulher só, primeiro, uma mulher só. Aí, ele percebeu que era o pássaro que estava fazendo comida. Resolveu conversar com o pássaro. Quando chegou ao acampamento, aquela tuiuiú viu ele, não tinha como se transformar em pássaro de novo. (M. 2012).

Antes ainda de prosseguir, insiste-se em remarcar como o narrador permanece se referindo ao jaburu-gente como pássaro, reiterando a premissa de que jaburu é pássaro e gente.

Em seguida, ele conta: Não sei como, pelo que eu entendi, no segundo acampamento, o pássaro aumentou para umas dez pessoas. As penas de tuiuiú são muitas, a pena de tuiuiú transformou como criança, velho, velha, jovem, aumentaram. (M. 2012).

A pluralidade não foi de mulheres, exclusivamente, as penas se transformaram em pessoas de distintos gêneros e de categorias de idade diversas formando uma aldeia. Aqui, o corpo poder se tornar muitos confunde-se como uma caracterização específica da aldeia do povo Jaburu, notadamente, a de que tem muitas pessoas e muitas casas. A manifestação empírica de o jaburu ter muitas penas é destacada e tomada como justificativa desta possibilidade de um corpo tornar-se muitos. A particularidade física do corpo do jaburu-ave impóe-se como uma referencial relevante nesta simbolização e parece ter centralidade neste momento.

Reitera-se que entre os jovens, os adultos e os mais velhos é comum fazer a correlação entre a quantidade de penas do jaburu e a da população formada pela metamorfose delas, pondo em relevo a multiplicidade: jaburu tem muita pena. Contudo, a grande quantidade revela que ela mesma é um atributo do Jaburu e que caracteriza o que se transforma de seu corpo, contornando onde está localizada uma relação de contiguidade entre o jaburu e as existências que se tornaram presentes pela transformação de seu corpo.

É especificamente desta ave que a mulher apareceu. A capacidade de se multiplicar pode ser vista como estendida de algum modo à mulher, configurando, igualmente, uma maneira dela ser percebida. Uma correlação entre a mulher e o Jaburu é feita neste sentido.

Há uma conexão entre a história do Jaburu e uma festa chamada suampiu, a qual celebra a primeira menstruação da mulher. A sogra e a esposa aparecem com uma pintura corporal específica caracterizada como sendo a do Jaburu. A presença desta particular subjetividade, contudo, ganha sentido por se tratar de uma festa ligada à mulher que, por sua vez, permanece sendo apreendida como uma 
transformação do jaburu. Denuncia que entre a ancestralidade e a atualidade inexiste fronteira. Ademais, por se referir à primeira menstruação, fica sugerido um destaque dado ao amadurecimento do corpo feminino associado à sua capacidade de poder tornar-se mais corpos. Antepóe-se, portanto, a ligação entre suampiu, jaburu, mulher e virar mais gente.

Schwartzman (1998) destaca na história do Jaburu o aparecimento da divisão clânica e o modelo de casamento exogâmico no modo de viver panará. Ewart (2000), igualmente, atribui este valor à referida história, além de enfatizar a diferenciação entre gente e animal, conforme discutido no início deste texto. Reitero esta íntima conexão desta narrativa com a divisão de pessoas panará em clãs, explorando ainda outros significados reveladores de uma específica percepção do corpo do jaburu.

A alta quantidade de pessoas transformadas das penas do jaburu conduz à divisão delas nos clãs kuositãtera, kwakiatãtera, krenoãtera e kwasôtãtera, traduzidos, respectivamente, como "povo da raiz do buriti"; "povo da folha do buriti"; "povo sem casa"; e "povo da costela" (Schwartzman 1988; Ewart 2000).

Os clãs ganham presença na condição de vida "com mulheres" e eles ocupam papel central no suampiu. Por ser a descendência matrilinear, sinaliza-se uma relação entre clã, jaburu e mulher. Homens e mulheres multiplicam-se de um clã, tal como do Jaburu apareceram homens e mulheres de várias categorias de idade, depois divididos em clãs. A possibilidade clânica, portanto, é dada pela multiplicação do Jaburu; aparece uma ligação dele com a multiplicação.

As pessoas transformadas do Jaburu foram divididas em clãs, o que sugere a ideia de que as novas pessoas multiplicadas descendem de clãs diferentes. Conforme o enunciado feito no contexto da festa suampiu: clã é como se fosse gente. (M. 1999), compreende-se que o poder de uma pessoa tornar-se muitas está impresso no clã, a matrilinearidade consolida a ideia de que esta potência da multiplicação é feminina, corporificada no clã.

É proibido o casamento com pessoas do mesmo clã; a exogamia é imperativa, o que faz resgatar a condição masculina anterior à presença dos clãs e da mulher. Eles fizeram a parceria com cada uma das mulheres que apareceram. Quando muitas mulheres surgiram, elas foram divididas entre os homens panará. Mas uma distinção é feita entre o coletivo jaburu e o humano, à medida em que a multiplicação de pessoas prosseguiu neste último sob a condição de uma aliança entre homem e mulher-jaburu, e não mais somente de uma multiplicação originada de um corpo feminino, absolutamente. Esta diferença entre o povo jaburu e o povo dos humanos panará está apoiada também no enunciado de um adulto, no contexto do referido seminário: jaburu agora vira do panará. (K. 2012). As famílias não são constituídas somente pelos jaburus, mas pela parceria deles com os homens.

Por ser o Jaburu significado como um afim é que se cogitou a possibilidade de um matrimônio com o homem panará, fabricando uma relação de parentesco. Compreende-se que os descendentes deste laço conjugal se percebem como consanguíneos do Jaburu, retomando a afirmativa de que "jaburu agora vira do panará”. A fim de desenvolver esta dimensão da alteridade, faço uma conexão com a formulação teórica de Viveiros de Castro (2000) de que a afinização de outrem é um dado, isto é, apreendida como um pressuposto sine qua non na cosmopráxis dos povos amazônicos. Identificamos aqui a expressão de uma ressonância disso com o evento etnográfico em discussão, chamando a atenção 
de que este se refere a um povo classificado como jê setentrional pois, na trajetória da disciplina, tende-se a distingui-lo dos povos amazônicos, mas, neste particular, vislumbra-se uma convergência. Os povos do Brasil Central, notadamente aqueles classificados como jê, entre os quais o povo Panará está incluído, tendem a ser identificados pelo pressuposto sociológico de uma unidade social com fronteiras identificáveis, animada por uma ordem interna estável e auto-reprodutiva, onde a aldeia circular, a divisão clânica, a prescrição exogâmica e a casa central impõem-se como instituições que regulam a produção de pessoas, orientada para a reiteração do centro social, embasando uma diferenciação nítida entre o interior e o exterior. Em contraposição, a ideia de uma socialidade mais ampla que abrange distintas alteridades, fundada numa lógica da incompletude e aberta ao desequilíbrio perpétuo é combinada aos povos amazônicos. Vale registrar que Ewart (2000) tem uma importante contribuição ao enfatizar, no povo Panará, a relação aberta com o exterior como parte constituinte de si mesmo, ultrapassando aquela tendência de investigar como a estrutura social de povos jê é produzida e reproduzida de maneira orgânica e ensimesmada, já revisada criticamente por tantos autores, destacando-se Coelho de Souza (2002).

Schwartzman (1988) esclareceu a importância das categorias classificatórias na construção de relações sociais na realidade do povo Panará, notadamente as ligadas ao clã, à matrilinearidade e à exogamia. Neste ponto, em especial, temos visto que elas mesmas configuram-se como desdobramentos da alteridade entre o homem panará e o Jaburu. A transformação corporal do Jaburu trouxe, paralelamente, mudança social, alterando a dinâmica da comunidade de homens panará; fez aparecerem os clãs e as mulheres. É importante esclarecer que este estudo está voltado a alteridades específicas, destituído da pretensão de uma generalização do "outro". Os contextos relacionais são situados e particularizados nesta abordagem em curso.

Neste momento do texto, enfatizo a importância de considerar as características empíricas do Jaburu na forma de ele ser simbolizado. A relação entre uma fisionomia e uma identidade de um sujeito é destacada, conforme será descortinado agora, traçando outros contornos nesta busca compreensiva.

Entre os diversos enunciados, é recorrente a explicação de que a mulher tuiuiú não era baixinha, era alta; o homem também era alto, até hoje consideramos que a mulher alta é parente do Tuiuiú. (M. 2012). A altura da ave é destacada na percepção sensorial do povo Panará como uma referência de contiguidade entre o humano e o Jaburu, atestada pela incidência de pessoas altas como se fosse a comprovação desta verdade. A altura é valorizada na construção simbólica contornando uma maneira de ver a si mesmo e ao jaburu.

Nesta oportunidade, trago para o texto o episódio de os Panará terem sido noticiados como índios gigantes no período em que a frente de contato liderada pelos irmãos Villas-Bôas concluiu a sua missão, em 19735. Orlando Villas-Bôas atestou cerca de oito pessoas bastante altas. Os sobreviventes do contato afirmam que tinham parentes muito altos, vítimas das epidemias decorrentes deste momento histórico. Um dos toputuns, categoria referente às autoridades da comunidade, notadamente

5 Vale informar que a FUNAI investiu nesta frente a favor do projeto de construção da BR-163 (Cuiabá-MT a Santarém-PA), cujo traçado incidia na área territorial habitada pelo povo Panará, tendo como proponente o governo militar dentro do Programa de Integração Nacional, na década de 70 do século XX. 
os mais velhos, chegou a nominar quatorze pessoas bem altas que ele conheceu, afirmando que tinha outros, cujos nomes não lembrou (Arnt; Pinto; Pinto 1998: 70). A foto abaixo é de um panará que foi capturado pelos Kaiapó Metuktire quando era criança (Arnt; Pinto; Pinto 1998: 70).

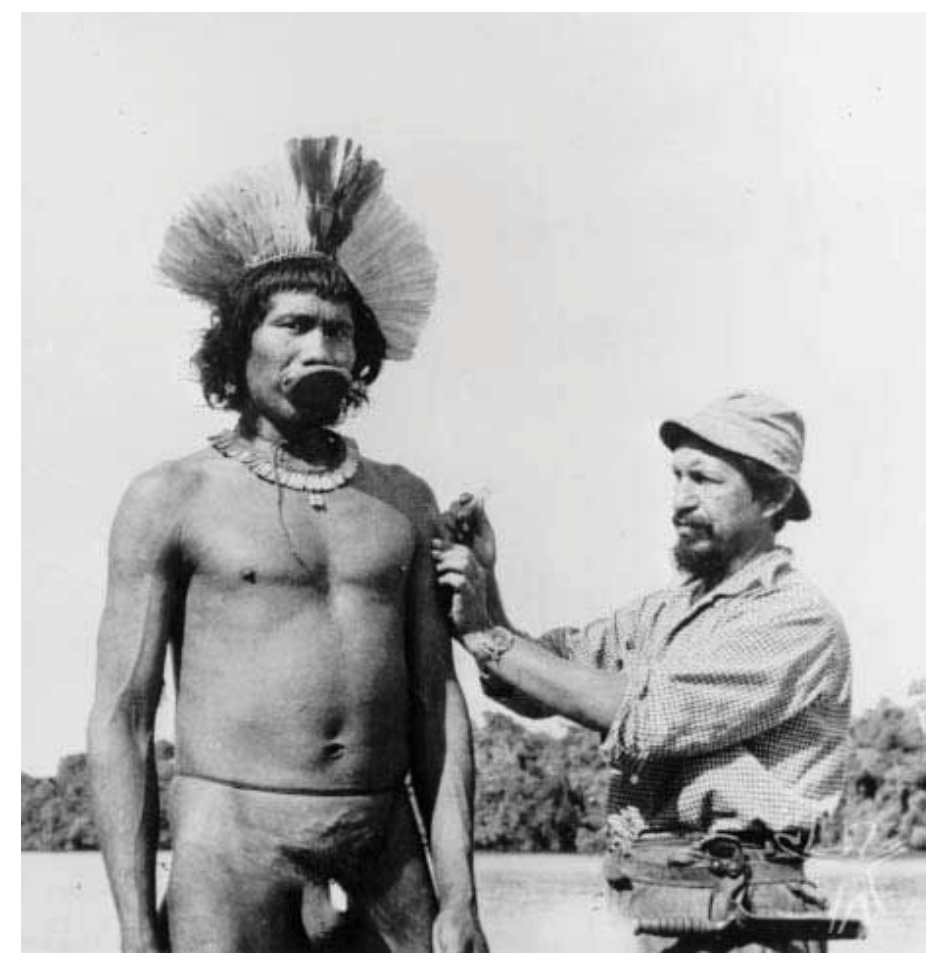

Foto: Arquivo pessoal de Orlando Villas-Bôas

Esta pessoa na imagem media 2,06 m conforme o registro de Arnt (Arnt; Pinto; Pinto 1998: 70); é interessante observar como a altura de alguns corpos humanos panará chamou a atenção dos não indígenas que participaram da conjuntura da referida política oficial de contato.

Entre os Panará, este fenômeno é compreendido como derivado do casamento com o Jaburu, remetendo ao fato de haver um vínculo entre a vivência dos ancestrais e a dos contemporâneos: Até hoje consideramos que mulher alta é parente do tuiuiú (M. 2012).

As percepções sensoriais influenciam na simbolização, fazendo presente a inscrição das características empíricas observadas. Outros aspectos fisionômicos são abordados: $O$ homem viu a vagina do Jaburu, ela tinha pelo no púbis, a da Anta não tem. As mulheres com esta mesma aparência são interpretadas como descendentes dessa ave.

A interação entre o humano e o Jaburu imprimiu mudança no corpo, o que sugere a formulação de que a alteridade está impressa na matéria. Embora a atividade sexual tenha acontecido com a versão humana do Jaburu, as qualidades ligadas ao corpo animal permaneceram nela inscritas. Vale relembrar que os homens e as mulheres transformados das penas do Jaburu eram altos. É difícil interpretar tal fenômeno discernindo o que pertence ao corpo humano ou ao do animal; é concebida uma relação de continuidade entre as formas físicas em ambas as circunstâncias corporais. É interessante observar que a fisionomia de uma pessoa é justificada a partir da mobilização de uma história do antigo, ocorrida na ancestralidade. A materialidade do corpo pode evocar a presença do Jaburu, remetendo à vivência do 
antigo homem panará, ascendente das gerações atuais. A alteridade na materialidade corporal apresenta outras nuances, envolvendo aspectos imateriais: Lá na aldeia não tem pessoa alta, só tem quatro. A preocupação nossa é porque o povo Panará está diminuindo, está sendo muito baixinho, não tem povo Panará alto. Acho que o jovem não cumpriu regra como o Tuiuiú cumpriu.

A predominância da população baixa em nossa atualidade é atribuída ao fato de não seguirem algumas regras ensinadas pelo Jaburu; e, pelo fato de os homens e as mulheres antigos as incorporarem, justifica-se a incidência de terem sido mais altos. A autoridade do Jaburu é reconhecida e os referidos ensinamentos são contemplados na pintura dele, na qual se usa urucum em toda a face, na parte inferior das pernas e na região do tórax. Na cerimônia do suampiu ela é praticada.

A pintura corporal não se realiza como uma representação simbólica do Jaburu e sim como de sua corporalidade mesma. Todavia, se ela é apresentada como uma regra, cujo descumprimento afeta a continuidade do tamanho alto do corpo, isto sugere, então, a ideia de que ela é também a forma de realizar a potência das qualidades físicas do Jaburu, quando a altura é considerada. A descontinuidade da regra não implica o esvaziamento do significado da descendência do Jaburu, na medida em que a presença do Jaburu ancestral permanece perpetuada. Porém, está em relevo a prática de um ato que ativa a presença dele no corpo, sendo celebrado este vínculo ancestral entre o homem e o Jaburu. A potência dele subsiste, o vir a ser alto como o Jaburu permanece como possibilidade.

Podemos identificar uma aproximação com as ideias de Viveiros de Castro (2002) quando este autor discute o simbolismo inscrito nas ornamentações corporais em contextos cerimoniais, argumentando que a fabricação da aparência animal visa à ativação de poderes de um outro corpo (idem: 393).

Mas, nesse estudo, é abstraída uma noção de corpo em que se credita a possibilidade do humano ser constituído pela descendência animal como uma imanência, independentemente da característica física realizar-se concreta ou potencialmente. A cor vermelha no pescoço e as penas brancas são reproduzidas no corpo humano, fazendo aparecer a presença do Jaburu ancestral na materialidade corporal em termos de emergir a relação do homem com ele na ancestralidade. Antepõe-se a relação em si mesma e não o jaburu, isoladamente; afinal, o parentesco é derivado de uma parceria.

É imperativa a ideia de que o corpo antropocêntrico não é puro e homogêneo. Há a inscrição da alteridade nele, as características fisionômicas de um humano denunciam a inscrição da agência do Jaburu. O caráter empírico no âmbito da materialidade do corpo é relevante e circunscreve uma maneira de simbolizar a referida espécie. Na forma humana, inscrevem-se formas animais: Jaburu agora vira do Panará (K. 2012), o que reitera a dimensão de um corpo humano com a potência de outro corpo. É neste sentido que a potência de outro corpo é ativada, o da inexistência de uma forma pura.

Tomando as condições de humanidade e animalidade como ferramentas conceituais, observo que o estatuto de sujeito do Jaburu não se baseia somente na sua capacidade cultural, à medida que específicas características materiais são mobilizadas na qualificação de sua particularidade, notadamente a alta quantidade de penas, por sua vez correlacionada à potência de um corpo se tornar muitos. Conforme dito, isto evoca o Jaburu ancestral significado como aquele que se multiplicou. Ainda que percebido como capaz de cozinhar, fazer bolo e outras ações humanas de caráter social, esta distinção corporal é enfatizada. 
Os corpos humanos panará, por sua vez, podem apresentar características físicas do Jaburu como a altura, relembrando que a mesma aparecia no jaburu-ave e no jaburu-gente, na ancestralidade. Portanto, a alteridade antropomórfica envolve a subjetividade do Jaburu e não uma de suas formas corporais. Igualmente, a potência de um corpo se multiplicar inscreve-se no corpo feminino panará, evocando o Jaburu ancestral, reiterando uma transversalidade entre o corpo humano e o do Jaburu. Contudo, atributos vinculados à condição de animalidade não diferenciam o corpo de uma espécie em particular, porque eles diferenciam o corpo humano também. Além disso, observamos que a metamorfose corporal se desdobrou em mudanças nas formas de construir relações sociais, trazendo ao mundo dos homens os clãs, a mulher e a possibilidade de uma parceria com ela.

O aparecimento da mulher instaurou uma mudança significativa na construção de relações sociais: antes eles "namoravam" com um buraco de pau, além de que os homens faziam beiju quando não tinha mulher, os homens assavam bicho para comer (P. 1998). A história do Jaburu retrata um convívio entre um homem panará e tal ave, pautado pelo interesse de um cuidar do outro, assemelhando-se àquelas formas de interação que envolvem parentes próximos e cônjuges na contemporaneidade. $\mathrm{O}$ termo "cuidar" é reincidente na narrativa, expresso pela reciprocidade no preparo e na oferta de alimento, enveredando para a constituição de um laço social matrimonial.

O desejo por um vínculo social é transversal nestes seres, traçando contornos de um corpo disposto a trocar com o outro sob a perspectiva de um cuidado mútuo. Neste particular, emerge ainda uma ligação desta relação homem e Jaburu com a partilha de alimento.

Nos momentos de uma expedição coletiva na mata, planejada para uma temporada prolongada, geralmente associada a uma ocasião festiva, as esposas e as mães acompanham com a finalidade de cuidarem dos caçadores, preparando-lhes o alimento, conforme é retratado na história do Jaburu. É íntima a relação entre mulher e preparação de alimento, evocando o cuidar do outro.

Esta imagem da parceria articulada ao cuidado mútuo é reencontrada no cotidiano, quando na cozinha ficam a esposa e o marido lhe fazendo companhia enquanto ela prepara o alimento, e a criançada perto brincando e correndo, pondo em relevo o laço conjugal e a constituição familiar, em que a preparação feminina de alimento permanece expoente. Peixe assado com beiju ou com cará; açaí com farinha e carne de porco assada; carne de macuco com beiju são algumas dentre as variadas refeições partilhadas nestes momentos.

Quando muitos porcos são caçados, as mulheres se juntam para preparar o alimento em quatro lugares da aldeia circular, ligados cada qual a um clã; quatro fogueiras se tornam referência para a reunião de mulheres de seu respectivo clã, cercadas por alguns filhos, explicitando uma associação entre preparação de alimentos e mulheres, tal como fundado pelo Jaburu ancestral. O clã converte-se em referência para a preparação e a partilha do alimento. Nesta última, abrange os maridos das mulheres de um dado clã, dada a uxorilocalidade.

No dia a dia, os homens casados visitam os seus parentes nas casas ligadas à região de sua família-natal, assim como as irmãs casadas se visitam levando os seus maridos que, por sua vez, necessariamente pertencem a outros clãs. Por meio do alimento, as relações entre os parentes do mesmo clã se desenvolvem e, no âmbito matrimonial, elas se estendem aos maridos com quem as irmãs se casaram. 
O alimento aparece na história do Jaburu como meio para a aproximação entre o pescador e o filhote do jaburu, construindo uma intimidade. Por meio do alimento, pode-se expressar uma intimidade já posta ou o interesse em edificá-la. Ele é criador e multiplicador de relações.

O casamento entre homem e mulher e as formas de preparar e circular o alimento são novidades que coincidem com esta passagem para um mundo em que os homens não estão mais sozinhos. Acontecem redimensionamentos na relação com o alimento, pondo em relevo a importância dele ser multiplicado e dividido também, salvaguardando que flexionam-se distintas formas dele circular de acordo com específicas situações cerimoniais e cotidianas.

A produção de pessoas associada ao matrimônio, por sua vez, está vinculada à maneira de perceber o corpo feminino, cujo poder de se tornar muitos impõe-se. A perpetuação da construção de alianças matrimoniais, portanto, torna-se possível por esta potência de multiplicação. Significados específicos são mobilizados na construção de contextos identificados como matrimônio, laços de afinidade, produção de pessoas e de alimento.

Agora vamos apresentar a outra história do surgimento da mulher na comunidade humana Panará na ancestralidade. Por meio dela, evidencia-se a reincidência desta dimensão da animalidade inscrever-se nas formas corporais de humano e animal. No entanto, procurarei evidenciar as nuances presentes, a fim de não incorrer em riscos de generalizações. Afinal, ainda persiste o teor investigativo nesta reflexão analítica em curso.

\section{História da relação com a Anta}

O significado do alimento associado ao cuidar do outro reaparece sob outra formatação na narrativa da anta, a qual igualmente trata do aparecimento da mulher na realidade panará. Articulando ambas as histórias, pode-se considerar que "transformar" correlaciona-se com alterar maneiras de se relacionar, bem como que a experiência ancestral do matrimônio dos antigos panará com o Jaburu e a Anta está impressa nas qualidades físicas dos atuais sujeitos panará. Em nossa contemporaneidade é entendido que descendente de anta é baixo e tem pouco pelo no púbis, de jaburu é alto e tem muito.

No período em que só existiam homens, conta-se que havia uma única senhora com quem eles praticavam relação sexual. Por não aguentar mais esta situação, um dia ela orientou que cada homem pegasse um pedaço de sua carne e o embrulhasse com gentileza em folhas de bananeira, garantindo que deles nasceriam mulheres com as quais os homens poderiam se casar. A gentileza enquanto um jeito de fazer exprime a relevância do afeto no comportamento social e na simbolização de um modo de se relacionar. Foi explicado: esta mulher era gente que a gente chama Anta. Era gente, quando a gente mata Anta, a gente divide (M. 2012). Compreende-se, portanto, que não é da anta na versão animal que procedeu a mulher, mas de uma pessoa identificada como Anta que, sob a forma corporal humana, interagia com os homens panará. A anta animal é, portanto, uma expressão desta referida Anta ancestral. É reiterada uma descentralidade na forma corporal antropomórfica ou animal, porque a anta é abordada como uma pessoa. 
Nas palavras de Viveiros de Castro (2002: 355), “[...] o mito fala de um estado do ser onde os corpos e os nomes, as almas e as ações, o eu e o outro se interpenetram, mergulhados em um mesmo meio pré-subjetivo e pré-objetivo". O sujeito nominado Anta implica a percepção de que o nome em si mesmo é a revelação de uma subjetividade específica, reconhecida como tal a partir da consideração de que os animais são ex-humanos. Ainda que sob a sua forma animal atual, a sua virtualidade como humana permanece. Schwartzman (1988), que conviveu por muito tempo com as famílias panará no tempo em que moraram no Parque Indígena do $\mathrm{Xingu}^{6}$, afirma em sua etnografia que os nomes são nomes de ancestrais, contemplando neste caso os animais, os pássaros, os peixes, as plantas, entre outros seres do cosmos (Schwartzman 1998: 251). É bastante interessante quando este autor informa que, na percepção panará, os nomes e os seres são Panará; além de terem as características que os configuram como tal, também têm atributos dos animais. É recorrente observar que, quanto à anta, é destacada a sua força, um atributo bastante valorizado, sobretudo nas ocasiões em que se precisa transportar e carregar coisas. A corrida de tora praticada principalmente em ocasióes cerimoniais, dentre elas o suampiu, é uma oportunidade para a exibição pública da força corporal.

A performance corporal e a fisionomia da anta são destacadas, reiterando que não é somente a capacidade reflexiva que contorna o estatuto de pessoa. Reconhece-se uma maneira de particularizar o corpo da anta, inscrita na caracterização desta específica subjetividade. Sob outros termos, referenciais empíricos e performáticos associados à animalidade podem ser transversais aos corpos humanos. Ter pouco pelo no púbis, ser gordinho e baixo evocam a anta ancestral, reincidindo a alteridade antropomórfica no corpo humano.

Quando se mata uma anta, os mais velhos da comunidade podem convocar pessoas, contemplando as mulheres, para irem à mata e transportar a anta de lá para a aldeia, passando-a de corpo a corpo do mesmo modo como fazem com a tora de buriti nestas referidas corridas cerimoniais. A conexão entre estes eventos de carregar a tora e carregar a anta é aqui registrada como uma expressão vinda de jovens panará, conforme testemunhei quando convivia com eles na aldeia Nãsêpotiti. A relação entre anta e força é sublinhada.

Viveiros de Castro (2002) caracteriza a cosmologia dos povos indígenas sul- americanos como multinaturalista, porque se acredita que a condição cultural, possibilitada pelo espírito, é homogênea às espécies, e que a diversidade incide nas formas corporais dos seres. Por outro lado, o autor qualifica a epistemologia das sociedades industriais como multiculturalista por acreditar que a condição comum e original das espécies está no campo biológico, da natureza, ao tempo que a diversidade está no âmbito da cultura, exclusiva à espécie humana. Aqui, a condição de humanidade é abordada nos mesmos termos já expostos acima, sendo consolidada a sua correlação com o "espírito". É a definição do que se tem como expressão de intencionalidade reflexiva, comunicativa e comportamental. Nesse aspecto é

6 A favor do projeto de construção da rodovia federal BR-163 (Cuiabá-MT - Santarém-PA), os irmãos Villas-Bôas gerenciaram a frente de atração do povo Panará, realizando o contato efetivo em 1973. Posteriormente à depopulação desenfreada, ao longo de dois anos, os sobreviventes foram transportados para o Parque Indígena do Xingu, em 1975, pela Força Aérea Brasileira e a Fundação Nacional do Índio. Lá permaneceram por 20 anos, tendo trocado sete vezes o lugar de habitação. Eles moraram com os Kaiapó, Kaiabi, Yudjá e Sujá. Dada a não identificação com o espaço físico, passaram a lutar pelo retorno ao lugar em que viviam. Em 1993, solicitaram ao presidente da FUNAI a demarcação da área que ocupavam, cuja delimitação resultou em grande perda do espaço vivido ainda hoje constituinte da memória histórica do povo Panará. A Terra Indígena Panará, cuja extensão é de 499.740 ha, está sendo habitada desde 1992. 
reconhecida como um atributo imanente aos animais, às plantas e aos astros, justificando o fenômeno de serem tratados como pessoas configurando relações intersubjetivas. Todos estão inseridos na mesma rede de relação social sociocósmica, inexistindo a distinção entre natureza e cultura (Viveiros de Castro 2002). Vê-se que a condição de humanidade é privilegiada para reconhecer o estatuto de pessoa, indistinto entre diversos seres do cosmos.

No contexto cultural do povo Panará é intrigante essa transversalidade de características físicas e comportamentais no Jaburu, na Anta e no humano, explicitando a inexistência de fronteiras entre as condições de animalidade e humanidade na caracterização de uma subjetividade. $\mathrm{O}$ corpo humano não é um modelo homogêneo e puro, nele inscreve-se a alteridade, exteriorizável na matéria, revelando que a diferenciação dos animais está combinada a uma específica forma de conceber o corpo humano, em que as condições de humanidade e animalidade coexistem. Com base em informações etnográficas registradas por Schwartzman (Schwartzman 1998:196), descendente do macaco-aranha tem pênis curto, e da anta, largo, o que sugere a continuidade de uma investigação neste aspecto.

A Anta, igual ao Jaburu, também apresentou o seu poder de se multiplicar em várias mulheres. A narrativa segue informando que os embrulhos bem cuidados viraram mulheres "bem gordinhas", já aqueles descuidados não se transformaram. Foi explicado: esta mulher era gente que a gente chama Anta. Era gente, quando a gente mata Anta, a gente divide (M. 2012). Compreende-se que foi da anta ancestral que outras apareceram, e o seu poder de se transformar corporalmente confundiu-se com o de se multiplicar em várias mulheres. Diversamente da narrativa do Jaburu, somente mulheres se transformaram da anta. Ainda que possibilite a transição para a realidade "com mulheres", não há uma associação entre anta e clã, tal como discutida anteriormente. No entanto, a multiplicação aqui permanece vinculada à construção de parceria entre homem e mulher.

Entre as pessoas panará, é invariável a apresentação de que a anta se submeteu voluntariamente a ser recortada, e foi quem deu a ideia de que isso fosse feito pelos homens, sublinhando o caráter intencional deste evento. Reitera-se, portanto, a premissa de uma metamorfose articulada à intencionalidade. O narrador fez uma conexão de que quando se caça a anta, ela é cortada em pedaços para distribuir às pessoas, todavia, esta condição de presa se refere à condição corporal da anta animal e não da anta ancestral. A possibilidade de a anta realizar-se como mulher e como alimento está posta sob a condição de uma metamorfose que distingue ambas as situações. Anta-gente é distinto de anta-animal.

A anta ancestral se multiplicou a fim de ser dividida aos homens, formando com eles uma parceria. A anta caçada é repartida, multiplicando-se em vários pedaços, e é partilhada como alimento pelas famílias. Um corpo permanece tornando-se muitos tanto na ancestralidade como na atualidade, porém, sob formas diversas.

Na vida comunitária, a prática de dividir a carne da anta, enquanto caça, é imperativa, sendo distribuída para várias famílias. Dividir a caça é uma conduta que tem relação de continuidade com aquela recomendada pela anta na ancestralidade. Este paralelo entre dividir a carne para alimentar as famílias e dividir as mulheres para cada homem mostra a intrínseca relação entre o aparecimento da mulher, a parceria e a partilha de alimento entre as famílias por ela formadas. Nesta oportunidade, inclui-se a consideração de que o jaburu não é valorizado como uma caça. 
Na história do Jaburu, a multiplicação resultou em homens, mulheres, jovens, adultos e crianças. É neste sentido que se compreende clã e a sua relação com o Jaburu, em que um corpo tornou-se muitos. Na história da Anta, a divisão dela enquanto alimento aparece como uma referência significativa nesta simbolização da capacidade de um corpo tornar-se muitos. Isto é considerado quando se apresenta que a mulher apareceu da anta por meio de uma divisão de sua carne. A ideia de multiplicação é reiterada, sugerindo a imagem de que a potência da mesma reside na mulher. $\mathrm{O}$ tamanho grande da anta permite ela ser cortada em muitos pedaços. Esta possibilidade de um virar muitos é destacada e o fato disso ser associado à imagem da mulher implica que, nesta última, reincide a imagem de poder pluralizar-se. Sob este prisma, vislumbra-se uma relação de continuidade entre as histórias do Jaburu e da Anta no sentido de darem centralidade à multiplicação e de a mesma estar fortemente associada à mulher. A formação de parcerias entre homem e mulher, por sua vez, foi possibilitada por corpos que têm a potência de virar muitos corpos, notadamente, os do Jaburu e da Anta.

A perpetuação desta multiplicação impõe-se no mundo "com mulheres", tornando possível a continuidade de um mundo com parceiras, à medida que a potência de tornar-se muitos permanece nas mulheres, expressando aquela retratada no Jaburu e na Anta dos quais as mesmas vieram.

Por fim, é evidenciado o paralelo entre dividir a carne para alimentar as famílias e dividir a carne para cada homem ter uma esposa para casar e criar a sua família.

\section{Considerações}

Antepõe-se a centralidade na identidade de uma subjetividade, independentemente de sua circunstância corporal, humana ou animal. Torna-se importante eleger como centro de reflexão o que constitui, então, a subjetividade da anta e do jaburu. A partir das histórias dos antigos explicativas da origem da mulher, foi observado que a condição da humanidade associada à consciência reflexiva e à capacidade comunicativa é incompleta para abarcar como o estatuto de sujeito é reconhecido nos ancestrais. Foi discutido como alguns atributos vinculados à condição de animalidade do jaburu e da anta são transversais à forma corporal humana destes mesmos sujeitos. E, por extensão, foi posta em relevo a alteridade antropomórfica na espécie humana, podendo inscrever-se nela os atributos de jaburu ou de anta. Mas antepõe-se que as diferenças físicas entre os panará se originam da relação do homem com o jaburu e a anta na ancestralidade: Mulher baixinha é parente da anta, saiu da anta, não da anta, na nossa lingua foi da velha; mulher alta é do tuiuiú. Para compreender este enunciado, é preciso nos remetermos à história dos antigos e apreender que é a relação em si mesma que constituiu a forma do corpo humano e que os atributos enfatizados, por sua vez, não são concebidos como exclusivos de uma forma humana ou animal destas subjetividades. Afinal, as mulheres e os homens jaburu, humanos, eram altos, tal como a forma do jaburu-ave; a gordura da anta é transversal a suas formas humana e de bicho. Ademais, podemos observar que inexiste uma forma homogênea e pura do corpo humano. Ele não é autorreferenciável porque está subjacente uma experiência relacional dos seus ascendentes com específicas subjetividades, notadamente, a anta e o jaburu. O jaburu agora vira do panará, o que reitera 
esta abordagem de um corpo constituído pela subjetividade do jaburu. Ainda precisam ser investigados mais casos para expandir esta reflexão.

Foi evidenciado, então, que a relação consanguínea entre humano e jaburu, assim como entre ele e a anta é cogitada como uma possibilidade, sendo ela abordada em termos de uma continuidade entre as formas humana e animal: jaburu-ave é alta, gente-jaburu é alta e parente humano de jaburu é alto. Desvela-se nesse ponto que o corpo evoca a presença da anta e do jaburu ancestrais, fazendo aparecer uma relação de continuidade entre a ancestralidade e a atualidade. Um dos aspectos traçados na noção de corpo panará é a alteridade antropomórfica que, paralelamente, evoca específicas subjetividades ancestrais no próprio corpo, reatualizando a experiência de seus ascendentes que com elas se relacionaram. A possibilidade do parentesco com o jaburu e a anta se articula à noção de corpo em que a animalidade e a humanidade são indissociáveis no corpo humano.

Entre as referidas narrativas há nuances na maneira de conceber a multiplicação como uma possibilidade, mas ela em si mesma parece operar como uma potencialidade recorrente nos corpos da anta e do jaburu. A potência de um corpo tornar-se muitos confunde-se com a mulher, à medida que a mesma aparece como uma transformação de específicas subjetividades significadas, por sua vez, com tal potência. A coexistência entre a humanidade e a animalidade reincide como um aspecto do corpo feminino. $\mathrm{O}$ corpo feminino humano panará é constituído de atributos que indicam uma relação de continuidade com os corpos do jaburu e da anta, reiterando a premissa de que o antropomorfismo não é puro, é constituído de atributos de outras subjetividades.

As palavras Jaburu e Anta aparecem como nomes de pessoas e, simultaneamente, referem-se a particulares características subjetivas, compreendendo aspectos físicos e performáticos. A força da anta reconhecida na sua capacidade de correr com pernas fortes é confundida como uma expressão dela mesma. A possibilidade dos humanos expressarem esta mesma qualidade pode ser concebida por meio de uma articulação com o que identifica a anta: "correr duro como a anta”. Quer dizer, a força é uma qualidade atribuída à anta e que os humanos podem, igualmente, manifestar, mobilizando sua conexão com a anta. Contudo, a subjetividade é configurada pela capacidade reflexiva, comunicativa, física e performática.

A dimensão afetiva está presente no delineamento dos contornos de uma noção de corpo. A consideração dela contribui para compreender a maneira de simbolizar a anta e o jaburu. Nas experiências interativas com cada um deles são destacadas distintas motivações que orientaram a conduta mútua entre os envolvidos, sendo imprescindível incluir os sentimentos como constituintes dos tipos de ações realizadas. A compreensão de como são simbolizados estes seres em questão contemplou, portanto, qual modo de relação pode ser concebido como possibilidade com eles. A significação pressupõe uma interação vivenciada e foi a partir desta perspectiva que se demonstrou a necessidade de atentarmos a qual afeto contornou a formação de um contexto relacional entre humanos e não-humanos. A especificação dos aspectos passíveis de serem abstraídos nos eventos de intersubjetividade permite o reconhecimento de que há variação de possibilidades afetivas, esquivando-se de uma generalização que fixe um tipo de afeto a uma subjetividade ou a uma forma de com ela interagir. Importa sublinhar a consideração de que as possibilidades afetivas são as mesmas entre humanos, jaburu e anta. 
A possibilidade de um corpo se transformar em vários é outro aspecto reincidente nas histórias do jaburu e da anta. Na história do jaburu a multiplicação de pessoas esteve fortemente ligada à partilha das mesmas voltadas à criação de parceria combinada ao cuidado mútuo. Na história da anta, a multiplicação de pessoas e a partilha das mesmas evocou a multiplicação e a partilha de alimentos. Rascunhamos contornos de um corpo disposto a trocar com o outro sob a perspectiva de um cuidado mútuo. Entre o homem e a mulher, a relação de parceria nos remete à dimensão da partilha entre aqueles que comungam a vida juntos.

Suspeita-se que o valor semântico inscrito nesta capacidade de multiplicação tenha relação direta com a produção de alimento e de pessoas, o que pretendo investigar mais. Na história do jaburu é mais explicitada a conexão entre mulher, clã, parceria e o cuidado mútuo, em que a preparação e a oferta do alimento realizam-se como uma maneira de ser cuidada pelo homem, cuidando dele.

Por fim, ainda que a pesquisa permaneça em curso, as reflexões acerca das informações acessadas e aqui partilhadas com o leitor sugerem que a humanidade e a animalidade são indissociáveis na percepção do corpo dos viventes no mundo, incluindo o humano.

\section{Adriana Werneck Regina é mestre em Educação pela UFMT e doutoranda em Antropologia pela UFSCar.}

\section{REFERÊNCIAS BIBLIOGRÁFICAS}

ARNT, Ricardo; Lúcio Flávio Pinto; Raimundo Pinto. 1998. Panará: a volta dos indios gigantes. São Paulo: Instituto Socioambiental.

BRASIL. Ministério da Educação; Fundação Nacional do Índio; Associação IPREN-RE. 2007. Mebêngôkre me Panãra me Tapajúnanhöpykakarõnejã. Panãra me Mebêngôkre me Tapajúna Jô kypaprepihãkia. Tapajuna me Panãra me Mebêngôkrenhöhwykakarõrötujare na itha. Atlas dos Territórios Mebêngôkre, Panará e Tapajúna. Brasília: MEC.

CARNEIRO FILHO, Arnaldo; Oswaldo Braga de Souza. 2009. Atlas de Pressões e Ameaças às Terras Indigenas na Amazônia Brasileira. São Paulo: Instituto Socioambiental.

COELHO DE SOUZA, Marcela Stockler. 2002. O traço e o círculo. O conceito de parentesco entre os jê e seus antropólogos. Tese de doutoramento em Antropologia Social. Rio de Janeiro: Universidade Federal do Rio de Janeiro.

16(46):69-96.

2001. "Nós, os vivos. A “construção do parentesco" entre alguns grupos Jê." RBCS

DESCARTES, René. 1996. Coleção Os Pensadores. São Paulo: Editora Nova Cultural.

DESCOLA, Philippe. 1986. "Le monde des jardins". In: La nature domestique: symbolisme et práxis dans l'écologie des Achuar. Paris: Ed. de la Maison des Sciences de L'Homme.

2001. “Construyendo naturalezas. Ecologia simbólica y práctica social”. In: Ph. Descola \& G. Pálsson (orgs.). Naturaleza e Sociedad. Perspectivas Antropológicas. México: Siglo Veintiuno Editores. 
DESCOLA, Philippe \& Gísli Pálsson (orgs.). 2001. Naturaleza e Sociedad. Perspectivas Antropológicas. México: Siglo Veintiuno Editores.

EWART, Elizabeth J. 2000. Living with each other: selves and alters amongst the Panara of Central Brazil. PhD Dissertation. London: University of London.

. 2005. "Fazendo pessoas e fazendo roças entre os Panará do Brasil Central". Revista de Antropologia (São Paulo) 48 (1): 9-35.

GIRALDIN, Odair. 1994. Cayapó e Panará. Luta e sobrevivência de um povo. Dissertação de Mestrado em Antropologia Social. Campinas: Universidade Estadual de Campinas.

INGOLD, Tim. 1995. "Humanidade e animalidade”. Revista Brasileira de Ciências Sociais 28 (10): 39-54.

.2004. "Culture on the ground, the world perceived through the feet". Journal of Material Culture 9 (3): 315-340.

KIERÃSÂ YÕ SÂTI. Diretor: Paturi Panará; Komoi Panará. Aldeia Nãsêpotiti, Terra Indígena Panará (MT\PA): Projeto Video nas Aldeias, 2005. DVD (51 min.), color., legendado.

LÉVI-STRAUSS, Claude. 1973. Antropologia Estrutural. Rio de Janeiro: Tempo Brasileiro. . 1993. Antropologia Estrutural II. Rio de Janeiro: Tempo Brasileiro.

. 1991. O Cru e o Cozido. Mitológicas. São Paulo: Brasiliense.

MAUSS, Marcel. 2003. Sociologia e Antropologia. São Paulo: Cosac Naify.

SCHWARTZMAN, Stephan. 1988. The Panara of the Xingu Nacional Park: the transformation of a society. PhD Dissertation. Chicago: University of Chicago.

1992. Os Panará do Peixoto de Azevedo e Cabeceiras do Iriri: História, Contato e

Transferência ao Parque do Xingu (Documentação do CEDI, 02/02/83; PZD 00019).

SEEGER, A.; Roberto Da Matta; Eduardo Viveiros de Castro. 1987. "A construção da pessoa nas sociedades indígenas brasileiras”. In João Pacheco de Oliveira (org.). Sociedades Indígenas e Indigenismo no Brasil. Rio de Janeiro: Editora UFRJ.

STRATHERN, Marilyn. 2004. Partial Connections. Oxford: Updated Edition.

VIVEIROS DE CASTRO, Eduardo. 2000. "Atualização e contra-efetuação do virtual na socialidade amazônica: o processo de parentesco". Ilha 2(1):5-46.

Naify. 2002. A inconstância da alma selvagem e outros ensaios de antropologia. São Paulo: Cosac .2012. "Cosmological perspectivism in Amazonia and elsewhere". Hau 1:45-168.

WAGNER, Roy. 2010. “Existem grupos sociais nas Terras Altas da Nova Guiné?”. Cadernos de Campo 19: 237-257.

.2012. A invenção da cultura. São Paulo: Cosac Naify.

WERNECK-REGINA, Adriana. 2013. Mitopoética na percepção da natureza na aprendizagem Panará. Dissertação de mestrado em Educação. Cuiabá: Universidade Federal de Mato Grosso. 


\title{
GENTE ALTA é PARENTE do TUIUIÚ, BAIXA É Da ANTA: ALTERIdAdes ANTRO- POMÓRFICAS
}

RESUMO: São partilhadas neste artigo reflexões sobre as qualidades destacadas pelos Panará quando reconhecem o estatuto de sujeito do jaburu e da anta. A partir de narrativas da origem da mulher e das práticas sociais a elas conectadas, é explicitado que a condição de humanidade é incompleta para identificar tais subjetividades e que a relação ancestral do homem com elas desdobrou-se em transformações nas maneiras de viver, bem como na forma corporal humana. Tornar inteligível a afirmativa de que gente alta descende de jaburu e baixa de anta entremeia o texto, contornando um antropomorfismo heterogêneo. Um corpo tornar-se muitos é outro aspecto explorado na simbolização do jaburu, da anta e da mulher, esta significada como surgida da transformação daquelas espécies. A alteridade antropomórfica no humano, evocando a presença destes ancestrais, explicita a coexistência da animalidade na espécie humana.

Palavras-chave: Panará; corpo; animalidade; alteridade; mulher.

TALL PEOPLE ARE TUIUIÚ 'S RELATIVE, SHORT ARE TAPIR'S: ANTHROPOMORPHIC ALTERITIES

\begin{abstract}
This article shares reflections on the qualities highlighted by the Panara when they recognize the subject status of the jaburu and the tapir. It is argued that narratives about the origin of women and of social practices connected to them elicit the incompleteness of human condition to identify such subjectivities, and that the ancestral relationship between man and each of them has changed ways of living, as well as the human body shape. The article is driven by the effort to make intelligible the assertion that tall people descend from the jaburu, and low people from the tapir, outlining a heterogeneous anthropomorphism. A body's capacity of becoming many is another aspect involved in the symbolization of the jaburu, the tapir and the woman, the latter being conceived as having come into being through the transformation of the former. By evoking the presence of those ancestors, anthropomorphic otherness makes explicit the animality in the human species.
\end{abstract}

Keywords: Panará; body; animality; otherness; woman.

RECEBIDO: 29/06/2016

APROVADO: $26 / 06 / 2017$ 